\title{
"A Study of Position Related Changes in Uroflowmetric Parameters Before \& After Treatment in Patients with Benign Prostatic Hyperplasia and Study of Revised Modified Luts Questionnaire in These Patients"
}

\author{
${ }^{1}$ Hemant Kamal, ${ }^{2}$ Dr. Mayank Mohan Agarwal, ${ }^{3}$ Dr. Arup Kumar Mandal, \\ ${ }^{4}$ Dr. Ravi Mohan Mavuduru, ${ }^{5}$ Dr. Kirti Kshetrapal \\ ${ }^{1}$ Assistant Professor Urology PGIMS Rohtak-124001 Haryana (India) \\ ${ }^{2}$ Ex- Asst. Prof. Urology PGIMER Chandigarh \\ ${ }^{3}$ Prof. Urology PGIMER Chandigarh \\ ${ }^{4}$ Asst. Prof. Urology PGIMER Chandigarh \\ ${ }^{5}$ Prof. Anaesthesia PGIMS Rohtak
}

\begin{abstract}
:
Objective: The aim of this study was to compare the uroflowmetric parameters in 3 different voiding positions before initial treatment for LUTS, compare position specific uroflowmetric parameters before \& after treatment \& to compare IPSS/AUA symptom index with study questionnaire(PGIMER questionnaire) before \& after treatment for LUTS.

Material \& methods: In total, 91 patients with symptomatic BPH were enrolled in this prospective controlled trial. The IPSS/AUA score was > 7/35 \& QOL was >2/6. Patients were divided into 2 groups i.e. one who did not receive any medical treatment for BPH \& others who were treated with alpha blockers. But the drug was discontinued for atleast $15 d$ before taking baseline measurements. The participants were asked to fill the IPSS/AUA questionnaire \& study questionnaire(which we have named as PGIMER Questionnaire) on 2 occasions i.e. before starting treatment \& $6 \mathrm{~W}$ after treatment. Uroflowmetry \& post void residual urine was checked in all 3 positions i.e. standing, sitting \& squatting position both before \& $6 \mathrm{~W}$ after treatment.

Results: In total, 91 patients were studied. There was no significant difference $(p>0.005)$ in uroflowmetric parameters in various voiding positions both before \& after treatment. Before treatment, strong correlation was found between IPSS voiding with PGIMER questionnaire voiding \& moderate correlation between IPSS storage \& PGIMER questionnaire storage symptom score. QOL in IPSS was moderately correlated with PGIMER questionnaire. After treatment, IPSS voiding score was strongly correlated with PGIMER voiding score \& weakly correlation of IPSS storage \& PGIMER questionnaire storage was found. QOL in IPSS was weakly correlated with PGIMER questionnaire.
\end{abstract}

Conclusion: There was no significant difference in uroflowmetric parameters in different voiding positions. Alpha blockers significantly improved the patient's symptom score \& global QOL index. The PGIMER questionnaire showed significant correlation with IPSS questionnaire.

\section{Introduction}

LUTS caused by BPH usually affects older man. Many patients with BPH have been treated by surgical procedures, others hesitate to undergo surgery. Minimally invasive treatment for LUTS \& BPH have been studied \& new studies are going on daily throughout world. The literature concerning alternative options for patients with BPH is extensive \& interesting ${ }^{1}$. The baseline evaluation in management of BPH includes DRE, determination of IPSS, urineanalysis, S.cr, PSA levels, uroflowmetry \& PVR ${ }^{2}$. UFM with PVR provides rapid \& convenient screening tool for effectiveness of act of voiding ${ }^{3,4}$. The effect of various voiding positions on uroflowmetric parameters remains largely unknown. The preferred voiding position of both men \& women is influenced by several factors including social, cultural \& medical. While most men prefer to void in standing position, others prefer squatting position. Women in our country used to void in squatting position, whereas in western countries, women prefer sitting position. There is growing trend towards conservative treatment of $\mathrm{BPH}^{5} \&$ taking a proper voiding position is regarded as a helpful recommendation in patients. Thus the study was undertaken to evaluate UFM findings in patients of symptomatic BPH in standing, sitting \& squatting positions \& also the effectiveness of alpha blockers with regards to uroflowmetric parameters in various voiding positions. Another most widely used parameter for assessment of LUTS in BPH patients is IPSS/AUA symptom score. But there are some pitfalls in scoring system like it does not address dysuria, incontinence, terminal dribbling which can be bothersome symptoms to many patients. Also the effect of bowel 
dysfunction on LUTS is also not assessed in current symptom score. Therefore in this present study, we have evaluated the severity \& impact(bother) of each individual LUTS \& bowel symptoms before \& after treatment using a simplified questionnaire, which we have named it as PGIMER symptom score questionnaire (PSSQ) \& comparing it with existing IPSS/AUA symptom score.

\section{Material \& Methods}

Patients with bothersome BPH with IPSS/AUA symptom score $>7 / 35$ \& QOL index $>2 / 6$ were divided into 2 groups: Treatment naive i.e. not received any medical treatment \& previously treated with some medications like alpha blockers/5-alpha reductase inhibitors. But these drugs were discontinued for atleast $15 \mathrm{~d}$ before taking baseline measurements. The participants were asked to fill 2 questionnaires - IPSS/AUA \& study questionnaire urinary/fecal symptoms (PSSQ). These were filled on 2 occasions i.e. before treatment \& 6-12 weeks after treatment. UFM was performed in each standing, sitting \& squatting position before \& 6-12 weeks after treatment. After each act of voiding, PVR was measured using abdominal USG.

\section{Results}

91 patients were included in study. Mean age was 63.8y (range 40-82y). Mean prostate volume was $42.3 \mathrm{ml}$ (range 11-118ml) .

\section{Discussion}

$\mathrm{BPH}$ is a condition intimately related to ageing ${ }^{6}$. Though not life threatening, its clinical manifestation as LUTS reduces patient's QOL ${ }^{7}$. Troublesome LUTS can occur in upto $30 \%$ men older than $65 y^{8}$. UFM is most commonly performed study in UDS. It is the initial screening test for evaluation of voiding function as it is simple, non-invasive \& inexpensive ${ }^{9}$. It is usually carried out in standing position in men but other positions like squatting or sitting may be utilized for social or medical reasons. Uroflowmetric measurements are affected by several factors like age, sex, voided volume \& voiding position ${ }^{10,11,12}$. Also there is correlation between uroflowmetric parameters \& defecatory symptoms. So the patients who have LUTS may likely to have defecatory symptoms. In our study the study questionnaire (PSSQ) voiding symptom score correlated well with storage symptom score $(\mathrm{r}=0.5, \mathrm{p}=0.0000) \&$ defecatory storage symptom score $(\mathrm{r}=0.2, \mathrm{p}=0.022)$ both before \& after treatment respectively. The study questionnaire storage, voiding score \& QOL index improved significantly in post treatment group $(\mathrm{p}=0.003,0.000,0.000$ respectively). IPSS storage, total score \& QOL improved significantly after treatment. However defecatory symptom score did not change significantly in post treatment group.

In our patients, we found cQmax \& cQave improved in standing position in post treatment group. PVR improved in all 3 positions. In our study, we also found that study questionnaire which we tabulated, there was moderate correlation between voiding \& storage symptom score \& between voiding symptom score with defecatory score both before $\&$ after treatment.

But the defecatory symptom score in study questionnaire did not improve after treatment with alpha blockers, indicating that both are 2 separate entities as far as treatment is concerned. We therefore suggest that uroflowmetry should be performed in a position which is convenient \& comfortable to patient. Adding alpha blockers to medical treatment improved patient's symptom score \& global QOL index.

\section{References}

[1]. Madersbacher S, Marberger M. Is transurethral resection of the prostate still justified? Br J Urol 1999; 83: 227-37.

[2]. Madsen FA, Bruskewitz RC. Clinical manifestations of benign prostatic hyperplasia. Urol Clin North Am 1995; 22: 291-8.

[3]. Webster GD, Guralnick ML. The neurourologic evaluation. In: Walsh PC, Retik AB, Vaughn ED, et al. (eds), Campbell's urology. 8th edition, Philadelphia: WB Saunders; 2002. p. 900-30.

[4]. Boone TB, Kim YH. Uroflowmetry. In: Nitti VW, editor. Practical urodynamics. Philadelphia: WB Saunders; 1998. p. $28-37$.

[5]. Lepor H. Natural histoty, evaluation, and nonsurgical management of benign prostatic hyperplasia. In: Walsh PC, Retik AB, Vaughan ED Jr, Wein AJ, editors. Campbell's urology. 7th ed. Philadelphia: WB Saunders; 1998. p. 1453-78.

[6]. Chute CG, Panser LA, Girman CJ, Oesterling JE, Guess HA, Jacobsen SJ, Lieber MM. The prevalence of prostatism: a population based survey of urinary symptoms. J Urol 1993; 150:85-89.

[7]. Donovan JL, Kay HE, Peters TJ, Abrama P, Coast J, Matos-Ferreira A, Rentzhog L, Bosch JL, Nordling J, Gajewski JB, Barbalias G, Schick E, Silva MM, Nissenkorn I, de la Rosette JJ. Using the ICSQoL to measure the impact of lower urinary tract symptoms on quality of life: evidence from the ICS-'BPH' study. International Continence Society - Benign Prostatic Hyperplasia. Br J Urol 1997; 80:712-21.

[8]. Chapple CR. BPH disease management. Eur Urol 1999; 36 (Suppl 3):1-6.

[9]. Neveus T, von Gontard A, Hoebeke P, et al. The standardization of terminology of lower urinary tract function in children and adolescents: Report from the Standardisation Committee of the International Children's Continence Society. J Urol 2006; 176:314324.

[10]. Boone TB, Kim YH: Uroflowmetry. In Nitti VW: Practical Urodynamics, Philadelphia, WB Saunders; 1998. p $28-37$.

[11]. Tessler J, Schick E. Does Urethral instrumentation affect uroflowmetry measurements? Br J Urol. 1990; 65: 261-263. 
"A Study of Position Related Changes in Uroflowmetric Parameters Before \& After Treatment in ..

[12]. Jorgensen JB, Jensen KM, Mogensen P. Age-related variation in urinary flow variables and flow curve patterns in elderly males. Br J Urol 1992; 69: 265-271. Observations :

Table 1: Demographic profile of the patients $(n=91)$

\begin{tabular}{|l|l|l|l|}
\hline & Mean \pm SD & Minimum & Maximum \\
\hline Age $($ years $)$ & $63.8 \pm 6.6$ & 40.0 & 82.0 \\
\hline Height $(\mathrm{cm})$ & $165.5 \pm 7.2$ & 150.0 & 184.0 \\
\hline Weight $(\mathrm{Kg})$ & $69.8 \pm 10.6$ & 50.0 & 94.0 \\
\hline BMI $\left(\mathrm{kg} / \mathrm{m}^{2}\right)$ & $25.5 \pm 3.7$ & 16.7 & 34.5 \\
\hline prostate size & $42.4 \pm 21.5$ & 11.0 & 118.0 \\
\hline
\end{tabular}

72 patients preferred to void in standing position, 8 in sitting position \& 11 in squatting position. Pretreatment uroflowmetric parameters are depicted in table 2,3,4,5 \& 6 which showed that there was no significant difference in various uroflowmetric parameters when compared between various positions, both before $\&$ after treatment.

Table 2: Uroflowmetric parameters in different voiding positions (pre treatment)

\begin{tabular}{|l|l|l|l|}
\hline \multirow{2}{*}{} & mean \pm SD & Squatting Position \\
\cline { 2 - 4 } & Standing Position & Sitting Position & $12.6 \pm 7.2$ \\
\hline Q max $(\mathrm{ml} / \mathrm{sec})$ & $12.5 \pm 7.2$ & $11.9 \pm 6.8$ & $6.4 \pm 4.0$ \\
\hline Qave $(\mathrm{ml} / \mathrm{sec})$ & $6.2 \pm 3.8$ & $6.3 \pm 3.9$ & $267.5 \pm 136.9$ \\
\hline VV $(\mathrm{ml})$ & $276.6 \pm 127.6$ & $261.7 \pm 129.4$ & $43.9 \pm 53.1$ \\
\hline PVR & $44.8 \pm 40.2$ & $45.2 \pm 46.3$ & $0.7 \pm 0.4$ \\
\hline cQmax & $0.7 \pm 0.4$ & $0.7 \pm 0.3$ & $0.4 \pm 0.2$ \\
\hline cQave & $0.4 \pm 0.2$ & $0.4 \pm 0.2$ & \\
\hline
\end{tabular}

Table 3: Standing versus Sitting

\begin{tabular}{|l|l|l|l|}
\hline & Standing Position $($ mean \pm SD) & Sitting Position $($ mean \pm SD) & p-value \\
\hline Q max $(\mathrm{ml} / \mathrm{sec})$ & $12.5 \pm 7.2$ & $11.9 \pm 6.8$ & 0.528 \\
\hline Qave $(\mathrm{ml} / \mathrm{sec})$ & $6.2 \pm 3.8$ & $6.3 \pm 3.9$ & 0.938 \\
\hline VV $(\mathrm{ml})$ & $276.6 \pm 127.6$ & $261.7 \pm 129.4$ & 0.934 \\
\hline CQ max & $0.7 \pm 0.4$ & $0.7 \pm 0.3$ & 0.441 \\
\hline CQAVE & $0.4 \pm 0.2$ & $0.4 \pm 0.2$ & 0.651 \\
\hline
\end{tabular}

Table 4 : Sitting versus Squatting

\begin{tabular}{|l|l|l|l|}
\hline & Sitting Position $($ mean \pm SD) & Squatting Position $($ mean \pm SD) & p-value \\
\hline Q max $(\mathrm{ml} / \mathrm{sec})$ & $11.9 \pm 6.8$ & $12.6 \pm 7.2$ & 0.948 \\
\hline Qave $(\mathrm{ml} / \mathrm{sec})$ & $6.3 \pm 3.9$ & $6.4 \pm 4.0$ & 0.976 \\
\hline VV $(\mathrm{ml})$ & $261.7 \pm 129.4$ & $267.5 \pm 136.9$ & 0.399 \\
\hline CQ max & $0.7 \pm 0.3$ & $0.7 \pm 0.4$ & 0.582 \\
\hline CQAVE & $0.4 \pm 0.2$ & $0.4 \pm 0.2$ & 0.494 \\
\hline
\end{tabular}

Table 5 : Standing versus Sitting

\begin{tabular}{|c|c|c|c|}
\hline & Standing Position $(\operatorname{mean} \pm$ SD) & Squatting Position $($ mean \pm SD) & p-value \\
\hline $\mathrm{Q} \max (\mathrm{ml} / \mathrm{sec})$ & $12.5 \pm 7.2$ & $12.6 \pm 7.2$ & 0.528 \\
\hline Qave $(\mathrm{ml} / \mathrm{sec})$ & $6.2 \pm 3.8$ & $6.4 \pm 4.0$ & 0.938 \\
\hline VV (ml) & $276.6 \pm 127.6$ & $267.5 \pm 136.9$ & 0.934 \\
\hline CQ max & $0.7 \pm 0.4$ & $0.7 \pm 0.4$ & 0.441 \\
\hline CQAVE & $0.4 \pm 0.2$ & $0.4 \pm 0.2$ & 0.651 \\
\hline
\end{tabular}

Table 6: Uroflowmetric parameters in different voiding positions (post treatment)

\begin{tabular}{|l|l|l|l|}
\hline \multirow{2}{*}{} & mean \pm SD & Sitting & Squatting \\
\cline { 2 - 4 } & Standing & $12.2 \pm 6.9$ & $12.7 \pm 7.6$ \\
\hline Q max $(\mathrm{ml} / \mathrm{sec})$ & $13.6 \pm 7.4$ & $6.4 \pm 4.2$ & $6.429 \pm 4.1$ \\
\hline Qave $(\mathrm{ml} / \mathrm{sec})$ & $6.7 \pm 4.1$ & $269.9 \pm 118.9$ & $279.5 \pm 119.3$ \\
\hline VV $(\mathrm{ml})$ & $277.3 \pm 132.6$ & $33.9 \pm 44.2$ & $32.8 \pm 46.2$ \\
\hline PVR $(\mathrm{ml})$ & $36.2 \pm 45.7$ & $0.7 \pm 0.4$ & $0.7 \pm 0.4$ \\
\hline cQmax & $0.8 \pm 0.4$ & $0.4 \pm 0.2$ & $0.4 \pm 0.2$ \\
\hline cQave & $0.4 \pm 0.2$ & & \\
\hline
\end{tabular}

Before treatment, strong correlation was found between IPSS voiding with PSSQ voiding \& moderate correlation between IPSS storage \& PSSQ storage

After treatment, IPSS voiding was strongly correlated with PSSQ voiding score \& moderate correlation between IPSS storage \& PSSQ storage.

QOL in IPSS was weakly correlated with PSSQ QOL. 